\section{Kidney \\ Blood Pressure Research}

Original Paper

\title{
Relationship Between Serum Uric Acid Levels and Intrarenal Hemodynamic Parameters
}

\author{
Hideki Uedono ${ }^{a}$ Akihiro Tsuda ${ }^{a}$ Eiji Ishimura ${ }^{a}$ Mari Yasumoto $^{a}$ \\ Mitsuru Ichii ${ }^{a}$ Akinobu Ochi ${ }^{a}$ Yoshiteru Ohno ${ }^{a}$ Shinya Nakatania \\ Katsuhito Moria Junji Uchida ${ }^{b}$ Tatsuya Nakatani ${ }^{\mathrm{b}}$ Masaaki Inaba ${ }^{\mathrm{a}}$
}

aDepartment of Nephrology, Department of Metabolism, Endocrinology and Molecular Medicine, bDepartment of Urology, Osaka City University Graduate School of Medicine, Asahi-machi,

Abeno-ku, Osaka, Japan

\section{Key words}

Uric acid • Inulin clearance • Para-aminohippurate clearance • Afferent arteriolar resistance

\begin{abstract}
Background/Aims: Hyperuricemia has been reported to affect renal hemodynamics in rat models. We evaluate the relationship between serum uric acid and intrarenal hemodynamic parameters in humans, utilizing the plasma clearance of para-aminohippurate $\left(C_{\mathrm{PAH}}\right)$ and inulin $\left(C_{\text {in }}\right)$. Methods: Renal and glomerular hemodynamics were assessed by simultaneous measurement of $C_{\mathrm{PAH}}$ and $C_{\text {in }}$ in 58 subjects. Of these, 19 subjects were planned to provide a kidney for transplantation; 26 had diabetes without proteinuria; and 13 had mild proteinuria. Renal and glomerular hemodynamics were calculated using Gomez's formulae. Results: $C_{\text {in }}$ was more than $60 \mathrm{ml} / \mathrm{min} / 1.73 \mathrm{~m}^{2}$ in all subjects. Serum uric acid levels correlated significantly with vascular resistance at the afferent arteriole $\left(R_{a}\right)(r=0.354, p=0.006)$, but not with that of the efferent arteriole $\left(R_{e}\right)$. Serum uric acid levels $(\beta=0.581, p=<0.001)$ were significantly and independently associated with $R_{a}$ after adjustment for several confounders $\left(R^{2}=0.518\right.$, $p=<0.001)$. Conclusions: These findings suggest, for the first time in humans, that higher serum uric acid levels are associated significantly with $R_{a}$ in subjects with $C_{\text {in }}>60 \mathrm{ml} / \mathrm{min} / 1.73 \mathrm{~m}^{2}$. The increase in $R_{a}$ in subjects with higher uric acid levels may be related to dysfunction of glomerular perfusion.
\end{abstract}

H. Uedono, A. Tsuda and E. Ishimura contributed equally to this work and thus share firs authorship.

Eiji Ishimura, MD, PhD.
Department of Nephrology, Osaka City University Graduate School of Medicine

1-4-3, Asahi-machi, Abeno-ku, Osaka 545-8585 (Japan)

Tel. +81-6-6645-3806, Fax +81-6-6645-3808, E-Mail ish@med.oska-cu.ac.jp 


\section{Kidney \\ Blood Pressure Research}

Kidney Blood Press Res 2015;40:315-322

\begin{tabular}{l|l}
\hline DOI: $10.1159 / 000368507$ & (C) 2015 S. Karger AG, Basel
\end{tabular}

Published online: June 08, 2015

www.karger.com/kbr

\section{Introduction}

It is well known that higher uric acid levels are associated with reduced glomerular filtration rate (GFR) [1-4]. The mechanism underlying renal dysfunction induced by higher uric acid levels has been explained in rats as occurring through endothelial dysfunction, which causes a decrease in nitric oxide synthesis, leading to an increase in the resistance of renal artery $[5,6]$. In a rat model, glomerular ischemia was induced by hyperuricemia [7]. Increases in resistance of the renal artery and decreases in renal plasma flow have been reported to be caused by hyperuricemia [8]. However, to date, there are no data supporting a relationship between serum uric acid levels and intrarenal hemodynamic parameters in humans with normal renal function. In humans, it is not possible to measure glomerular hemodynamic variables directly. However, Gomez published a series of formulae for the indirect evaluation of glomerular hemodynamics in humans [9]. These formulae have been used to calculate glomerular hemodynamics in various conditions, including untreated and treated essential hypertension $[9,10]$, renovascular hypertension in human [11], primary aldosteronism [12], and supraventricular tachycardia [13], and diabetic and non-diabetic subjects by us $[14,15]$. The aim of the present study was to evaluate the relationship between serum uric acid levels and renal hemodynamic parameters in humans, utilizing clearance of para-aminohippurate $\left(\mathrm{C}_{\mathrm{PAH}}\right)$ and inulin $\left(\mathrm{C}_{\text {in }}\right)$

\section{Subjects and Methods}

\section{Subjects}

The study protocol was approved by the Ethics Committee of Osaka City University Graduate School of Medicine (\# 1444). The study was performed as a single-center study at Osaka City University Hospital between January 2010 and August 2014. Subjects with preserved renal function were consecutively included after written informed consent to precisely examine the renal function was obtained. Subjects with GFR measured by $C_{\text {in }}$ as being less than $60 \mathrm{~mL} / \mathrm{min} / 1.73 \mathrm{~m}^{2}$ were excluded from the analysis, since these subjects were considered to have severely impaired renal hemodynamics and would be inappropriate for the application of Gomez formulae.

Fifty-eight subjects (55.6 \pm 13.2 years old, 25 males and 33 females) were examined in the present study. Of these, 19 subjects were planned to provide a kidney for transplantation; 26 had diabetes without proteinuria; and 13 had mild proteinuria (urine protein $\leq 1+$ by the dipstick test, no hematuria). They were admitted to Osaka City University Hospital for the evaluation of renal function.

Measurement of $C_{\text {in }}$ and $C_{P A H^{\prime}}$ and calculation of intrarenal hemodynamic parameters

Renal plasma flow (RPF) and glomerular filtration rate (GFR) were determined by the constant input clearance technique using PAH and inulin, respectively, as previous reported by us $[14,15]$. Continuous intravenous infusion of $1 \%$ inulin and $0.5 \% \mathrm{PAH}$ via the antecubital vein was performed in the morning after an overnight fast, based on the method of Horio et al. [16]. $\mathrm{C}_{\mathrm{PAH}}$ and $\mathrm{C}_{\mathrm{in}}$ were measured simultaneously using a simple method based on a single urine collection. In brief, subjects received $500 \mathrm{ml}$ of water orally $15 \mathrm{~min}$ before infusion. After a priming dose of PAH and inulin, the rates of infusion were set a $300 \mathrm{ml} / \mathrm{h} \mathrm{for}$ the first $30 \mathrm{~min}$ and $100 \mathrm{ml} / \mathrm{min}$ for the remaining time. To maintain hydration, $180 \mathrm{ml}$ of water was given orally. Subjects completely emptied their bladder at $45 \mathrm{~min}$ after the start of the test and urine was collected for measurement of urinary PAH and inulin. The urine collection period was set at 90 min to increase the accuracy of the clearance study. Blood samples for the measurement of serum PAH and inulin were taken at the beginning and end of the clearance period.

$\mathrm{C}_{\mathrm{PAH}}$ and $\mathrm{C}_{\mathrm{in}}$ were calculated by the UV/P method (U: concentration in urine, $\mathrm{V}$ : urine volume [ml/min], $\mathrm{P}$ : concentration in plasma) using the mean serum $\mathrm{PAH}$ and inulin concentrations at the beginning and end of the clearance period. Plasma PAH and inulin concentrations were determined colorimetrically using the $\mathrm{N}-1$ naphthylethylenediamine and anthrone method, respectively, with a Corning 258 spectrophotometer [17-19]. 


\section{Kidney \\ Blood Pressure Research}

Kidney Blood Press Res 2015;40:315-322

\begin{tabular}{l|l}
\hline DOI: $10.1159 / 000368507$ & (C) 2015 S. Karger AG, Basel
\end{tabular}

Published online: June 08, 2015

www.karger.com/kbr

While direct measurement of glomerular hemodynamics parameters in humans is not feasible, the formulae introduced by Gomez [9] allow indirect assessment of glomerular hemodynamics, as recently discussed in detail by Guidi et al. [20]. These formulae were designed for quantitative estimation of filtration pressure across the glomerular capillaries $(\Delta \mathrm{PF})$, glomerular hydrostatic pressure $\left(\mathrm{P}_{\text {glo }}\right)$, and afferent and efferent arteriolar resistances ( $\mathrm{R}_{\mathrm{a}}$ and $\mathrm{R}_{\mathrm{e}^{\prime}}$, respectively) using measured blood pressure, $\mathrm{GFR}$, as measured by $\mathrm{C}_{\text {in }}, \mathrm{RPF}$, as measured by $\mathrm{C}_{\mathrm{PAH}}$, hematocrit, and plasma protein concentrations under the assumptions that (1) intrarenal vascular resistances can be divided into three compartments: afferent, efferent and venular; (2) hydrostatic pressures in the venules, interstitium, renal tubules and Bowman's space $\left(\mathrm{P}_{\text {Bow }}\right)$ are in equilibrium at a value of approximately $10 \mathrm{mmHg}$; (3) the gross filtration coefficient $\left(\mathrm{K}_{\mathrm{FG}}\right)$ is $0.0406 \mathrm{ml} / \mathrm{s}$ per mmHg per kidney; and (4) filtration disequilibrium is postulated along the glomerular capillaries $[9,20]$.

The Gomez formulae were calculated from the original paper as follows:

$\Delta \mathrm{P}_{\mathrm{F}}=\mathrm{GFR} / \mathrm{K}_{\mathrm{FG}}$

$\mathrm{P}_{\text {glo }}=\Delta \mathrm{P}_{\mathrm{F}}+\mathrm{P}_{\text {Bow }}+\pi \mathrm{G}$

$\pi \mathrm{G}=5 \cdot\left(\mathrm{C}_{\mathrm{M}}-2\right)$

$\mathrm{C}_{\mathrm{M}}=\mathrm{TP} / \mathrm{FF} \cdot \ln (1 /(1-\mathrm{FF}))$

In the above, $\Delta \mathrm{P}_{\mathrm{F}}$ was the filtration pressure across the glomerular capillary. $\mathrm{K}_{\mathrm{FG}}$ (the gross filtration coefficient) was estimated as $0.0406 \mathrm{~mL} / \mathrm{sec} \cdot \mathrm{mm} \mathrm{Hg}$ per kidney. $\mathrm{P}_{\text {Bow }}$ (the hydrostatic pressure in Bowman's space) was estimated as $10 \mathrm{~mm} \mathrm{Hg}$; $\pi \mathrm{G}$ (the oncotic pressure within the glomerular capillaries) can be obtained from $\mathrm{C}_{\mathrm{M}}$ (plasma protein concentration within the glomerular capillaries), and calculated from the $\mathrm{TP}$ (total protein concentration) and filtration fraction (FF).

From Ohm's law:

$\mathrm{R}_{\mathrm{a}}=\left(\left(\mathrm{MBP}-\mathrm{P}_{\text {glo }}\right) / \mathrm{RBF}\right) \cdot 1328$

$\mathrm{R}_{\mathrm{e}}=\left(\mathrm{GFR} / \mathrm{K}_{\mathrm{FG}} \cdot(\mathrm{RBF}-\mathrm{GFR})\right) \cdot 1328$

$\mathrm{RBF}$ can be calculated from RPF and hematocrit (Ht) using the standard formula:

$\mathrm{RBF}=\mathrm{RPF} /(1-\mathrm{Ht})$

In the above, 1328 is the conversion factor to dyne $\cdot \mathrm{sec} \cdot \mathrm{cm}^{-5}$; GFR (glomerular filtration rate), RPF (renal plasma flow), and RBF (renal blood flow) are expressed in $\mathrm{mL} / \mathrm{sec}$; and the mean blood pressure (MBP) is calculated as ( $2 \mathrm{x}$ diastolic $\mathrm{BP}+$ systolic $\mathrm{BP}) / 3$. In the present study, Gomez formulae were applied in subjects with $\mathrm{C}_{\text {in }}>60 \mathrm{ml} / \mathrm{min} / 1.73 \mathrm{~m}^{2}$.

\section{Statistical analysis}

Results are expressed as the mean \pm standard deviation (SD). Correlations between two variables were examined using Pearson's correlation coefficient. Multiple regression analyses were performed to evaluate the relationships between $\mathrm{R}_{\mathrm{a}}$ and other parameters. All analyses were performed using StatView 5 for Windows (SAS Institute Inc., Cary, NC, USA). The level of significance was set at $p<0.05$.

\section{Results}

\section{Baseline characteristics}

Baseline characteristics of the subjects are shown in Table 1. The mean age was 55.6 \pm 13.2 years old, and 25 subjects $(43.1 \%)$ were male. The mean serum creatinine level was $0.7 \pm 0.2 \mathrm{mg} / \mathrm{dl}$. GFR measured by $\mathrm{C}_{\text {in }}$ was $86.0 \pm 20.2 \mathrm{ml} / \mathrm{min} / 1.73 \mathrm{~m}^{2}$, being $>60 \mathrm{ml} /$ $\min / 1.73 \mathrm{~m}^{2}$ in all subjects.

The mean blood pressure was $92 \pm 11 \mathrm{mmHg}$, and 22 subjects (37.9\%) were receiving antihypertensive therapy with an angiotensin receptor blocker (ARB) and/or angiotensin converting enzyme (ACE) inhibitor $(n=20)$, and/or a calcium channel blocker $(n=10)$. Antihyperuricemia agents (allopurinol) were prescribed in three subjects.

The plasma glucose and $\mathrm{HbA} 1 \mathrm{c}$ values were $107 \pm 29 \mathrm{mg} / \mathrm{dL}$ and $6.7 \pm 1.8 \%$, respectively, with 26 subjects diagnosed as having type 2 diabetes mellitus based on a history of diabetes or the criteria in the Report of the Expert Committee on the Diagnosis and Classification of Diabetes Mellitus [21]. 


\section{Kidney \\ Blood Pressure Research}

Table 1. Clinical characteristics of the subjects

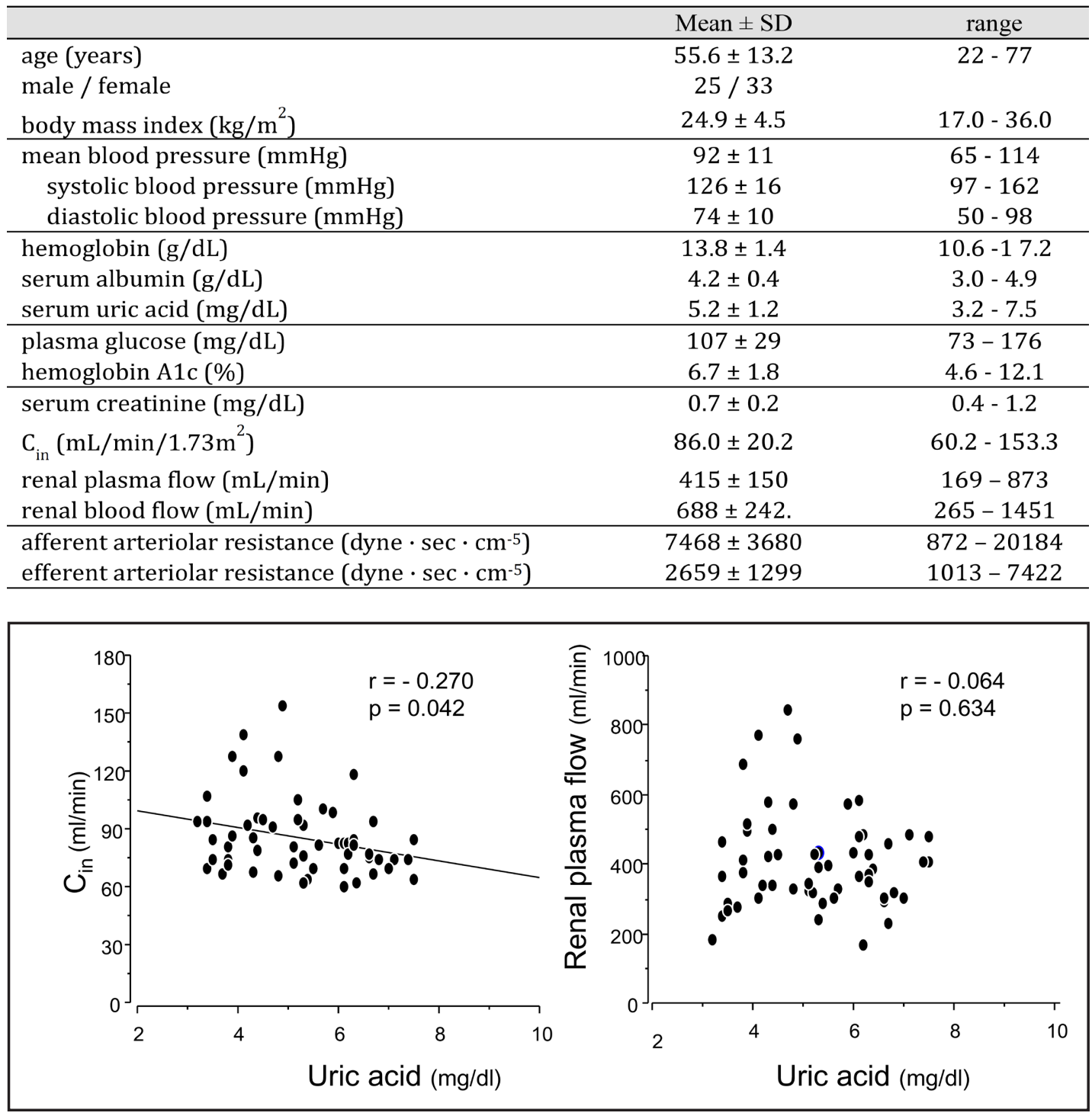

Fig. 1. Relationship between serum uric acid levels and inulin clearance $\left(C_{\text {in }}\right)$ and renal plasma flow. There was a significant, negative correlation between serum uric acid levels and $C_{i n}$.

Relationship between serum uric acid and each of the renal hemodynamic parameters

We examined the relationship between serum uric acid levels and renal hemodynamic parameters. Serum uric acid showed a significant negative correlation with $C_{i n}(r=-0.270$, $\mathrm{p}=0.0421$ ). However, there were no significant correlations between serum uric acid levels and renal plasma flow, or renal blood flow $(r=-0.064, p=0.634, r=-0.0018, p=0.892$, respectively) (Figure 1).

Multiple regression analyses were performed to examine whether serum uric acid levels were associated with $\mathrm{C}_{\text {in }}$ after adjustment for age, gender, body mass index, blood pressure and serum albumin. Serum uric acid levels were not associated with decreasing $\mathrm{C}_{\text {in }}$ (Table 2).

The relationships between serum uric acid levels and the resistance of the afferent $\left(R_{a}\right)$ and efferent $\left(R_{e}\right)$ arterioles were examined. As shown in Figure 2, serum uric acid levels correlated positively with $R_{a}(r=0.354, p=0.0064)$, but not with $R_{e}(r=-0.250, p=0.158)$. 


\section{Kidney \\ Blood Pressure \\ Research}

Table 2. Factors associated with $\mathrm{C}_{\mathrm{in}}$ and $\mathrm{R}_{\mathrm{a}}$. (Multiple regression analysis)

\begin{tabular}{|c|c|c|c|c|}
\hline & & & & \\
\hline & $\beta$ & $\mathrm{p}$ & $\beta$ & $\mathrm{p}$ \\
\hline age (year) & -0.105 & 0.477 & 0.106 & 0.3566 \\
\hline gender $($ male $=0$, female $=1)$ & 0.031 & 0.834 & 0.309 & 0.0078 \\
\hline body mass index $\left(\mathrm{kg} / \mathrm{m}^{2}\right)$ & -0.037 & 0.807 & -0.237 & 0.0477 \\
\hline systolic blood pressure (mmHg) & -0.095 & 0.482 & 0.480 & $<0.0001$ \\
\hline serum albumin (g/dL) & 0.204 & 0.130 & -0.192 & 0.0713 \\
\hline hemoglobin A1c (\%) & 0.232 & 0.115 & 0.069 & 0.544 \\
\hline serum uric acid $(\mathrm{mg} / \mathrm{dL})$ & 0.256 & 0.104 & 0.581 & $<0.0001$ \\
\hline $\mathrm{R}^{2}$ & & & & \\
\hline $\mathrm{P}$ & & & & \\
\hline
\end{tabular}

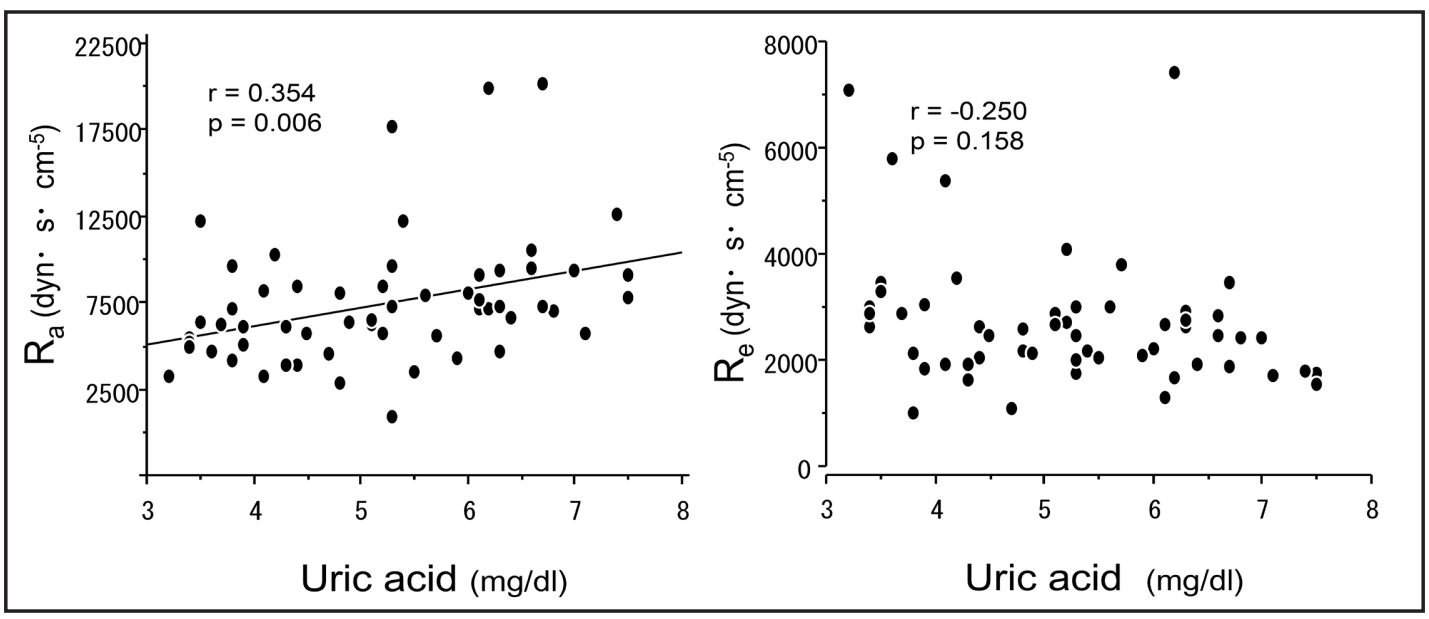

Fig. 2. Relationship between serum uric acid levels and resistance of the afferent $\left(R_{a}\right)$ and efferent $\left(R_{e}\right)$ arterioles. There was a significant positive correlation between $\mathrm{R}_{\mathrm{a}}$ and serum uric acid levels, but not between $\mathrm{R}_{\mathrm{e}}$ and serum uric acid levels.

As shown in Table 2, multiple regression analysis was performed to examine whether serum uric acid levels were associated with $\mathrm{R}_{\mathrm{a}}$ after adjustment for age, gender, body mass index, blood pressure, serum albumin and hemoglobin A1c. Female gender, hypertension, hypoalbuminemia and higher serum uric acid levels were significantly and independently associated with increased $R_{a}$.

\section{Discussion}

In the present study, we examined the relationship between serum uric acid levels and renal hemodynamic parameters in subjects with $\mathrm{C}_{\text {in }}>60 \mathrm{ml} / \mathrm{min} / 1.73 \mathrm{~m}^{2}$.

We demonstrated that serum uric acid levels correlated significantly and positively with $R_{a^{\prime}}$ but not with $R_{e}$. Multiple regression analysis also showed that $R_{a}$ was associated significantly and independently with serum uric acid levels after adjustment for several confounders.

Sanchez-Lozada et al. reported that afferent arterial thickening with increased $\alpha$-smooth muscle actin staining of the media was seen in hyperuricemic rats [22]. Further, the authors also reported that hyperuricemia-induced arteriolopathy in preglomerular vessels, which possibly impairs the autoregulatory response of afferent arterioles, produces renal hypoperfusion [23]. In addition, lumen obliteration induced by vascular wall thickening results in severe vasoconstriction, decreasing renal plasma flow, GFR, and perfusion to peritubular 


\section{Kidney Blood Pressure Research}

Kidney Blood Press Res 2015;40:315-322

\begin{tabular}{l|l}
\hline DOI: $10.1159 / 000368507$ & (C) 2015 S. Karger AG, Basel
\end{tabular}

Published online: June 08, 2015

www.karger.com/kbr

capillaries [23]. The resulting ischemia is a potent simulus that induces tubulointerstitial inflammation and fibrosis, as well as arterial hypertension [23]. Khosla et al. reported that nitric oxide was reduced in hyperuricemic rats [6]. Uric acid has also been reported to inhibit nitric oxide production in endothelial cells [6]. These experimental results in rats indicate that hyperuricemia induced endothelial dysfunction, i.e., impaired nitric oxide production, and hyperuricemia-induced arteriolopathy, particularly in the afferent arteriole. Increased resistance of the afferent arteriole, as seen with higher serum uric acid levels in the present study, is considered to be consistent with these experimental results.

In humans, the relationship between uric acid and kidney disease is more complicated because of the many confounding variables. Serum uric acid levels have been reported to be associated with other risk factors for kidney disease, such as hypertension, insulin resistance and microalbuminuria [24, 25]. In the present study examining subjects with preserved renal function, a significant, negative correlation was found between serum uric acid and $\mathrm{C}_{\text {in }}$ in the univariate analysis, but not in the multivariate analysis, indicating that the association between increased uric acid and decreased GFR was confounded substantially by various risk factors. Potential mechanisms underlying the kidney damage from uric acid have been reported to include induction of afferent arteriopathy, inflammation and activation of the renin-angiotensin system [24, 26]. Kohagura et al. demonstrated, by renal biopsy examination, that hyperuricemia was significantly and independently associated with renal arteriolar hyalinosis and higher grade wall thickening, suggesting that higher uric acid may cause progression of chronic kidney disease (CKD) through its effect on arterioles [27]. Weiner et al. reported that serum uric acid is a modest independent risk factor for incident CKD in the general population [3]. Bellomo et al. also reported that serum uric acid level is an independent risk factor for decreased kidney function [28]. The mechanisms of uric acid on incident CKD have been considered to be the direct toxic effect of uric acid on the kidney, via exacerbation of hypertension [3, 27, 28]. In humans, it has been reported that the highest tertile of serum uric acid levels was associated with incident kidney injury, not associated with progression of kidney injury [29]. However, Iseki et al. reported that hyperuricemia is associated with the progression of CKD to end-stage renal disease [2]. We demonstrated that higher serum uric acid levels were associated with increased $\mathrm{R}_{\mathrm{a}}$ in the present study. The increase in $\mathrm{R}_{\mathrm{a}}$ with higher uric acid levels may cause impaired or dysregulated perfusion of the glomeruli, which could be related to the decreased renal function in subjects with GFR $>60 \mathrm{~mL} / \mathrm{min} / 1.73 \mathrm{~m}^{2}$. However, from the present study, it cannot be directly elucidated whether increased $\mathrm{R}_{\mathrm{a}}$ with higher serum uric acid levels causes decreased GFR, in part since our study did not show a significant association between serum uric acid levels and GFR $\left(\mathrm{C}_{\text {in }}\right)$ in multiple regression analysis.

In the present study, female gender was a significant, independent factor associated with increased $\mathrm{R}_{\mathrm{a}}$ in multiple regression analysis. Iseki et al. [1] reported that hyperuricemia was an independent predictor of end stage renal disease (ESRD) in women. In women aged 51 years and older, serum uric acid levels have been shown to be increased, suggesting a role of estrogen [30]. Considering our current results with these previous studies, the risk for ESRD conferred by serum uric acid levels may be greater among women than men.

There are some limitations to the present study. Firstly, the study was performed in a relatively small number of Japanese subjects, and a large-scale study is needed to confirm that hyperuricemia increases $\mathrm{R}_{\mathrm{a}}$. Secondly, some of the subjects took antihypertensive agents, including RAS inhibitors. However, since these inhibitors have been reported to mainly affect efferent arterioles and decrease $R_{e}[31,32]$, we consider that the use of RAS inhibitors cannot explain the increase of $\mathrm{R}_{\mathrm{a}}$. Thirdly, we did not directly measured the renal hemodynamics, since it is impossible to measure it in humans. Instead, we used Gomez's formulae to calculate renal hemodynamics. Although the formulae are based on several assumptions, many studies have validated the clinical utility of the formulae $[11-13,15]$. Fourthly, our cohort of relatively small number of subjects consisted of rather heterogeneous groups of healthy subjects $(n=19)$, diabetic subjects without proteinuria $(n=26)$, and mild 


\section{Kidney \\ Blood Pressure Research}

Kidney Blood Press Res 2015;40:315-322

\begin{tabular}{l|l}
\hline DOI: 10.1159/000368507 & (C) 2015 S. Karger AG, Basel
\end{tabular}

Published online: June 08, 2015

www.karger.com/kbr

proteinuria subjects $(n=13)$. This was partly as a result of difficulties in obtaining informed consent to our study; due to the complex infusion techniques and timed blood and urine collection. However, in all subjects, GFR measured by $\mathrm{C}_{\text {in }}$ was more than $60 \mathrm{~mL} / \mathrm{min} / 1.73 \mathrm{~m}^{2}$. Serum uric acid levels were not significantly different between the healthy $(5.0 \pm 1.5 \mathrm{mg} / \mathrm{dL})$, diabetic (5.3 $\pm 1.5 \mathrm{mg} / \mathrm{dL})$ and mild proteinuria $(5.5 \pm 1.7 \mathrm{mg} / \mathrm{dL})$ subjects. Further studies are required to examine renal hemodynamics separately in each of the three groups. Lastly, we did not measure how $\mathrm{R}_{\mathrm{a}}$ was affected when serum uric acid levels were reduced with anti-hyperuricemia agents. In the present study, there were only three subjects undergoing treatment with anti-hyperuricemia agents. It is necessary to confirm that $\mathrm{R}_{\mathrm{a}}$ is reduced by these agents, in future studies.

\section{Conclusion}

The findings of the present study demonstrate, for the first time in humans, that higher serum uric acid levels were associated significantly with increased $R_{a}$. The increase in $R_{a}$ in those subjects with higher uric acid levels may be related to dysfunction of glomerular perfusion.

\section{Disclosure Statement}

The authors declare that there is no conflict of interest that could be perceived as prejudicing the impartiality of the reported research.

\section{Acknowledgements}

This study was not funded by a grant from a funding agency in the public, commercial or not-for-profit sector.

\section{References}

1 Iseki K, Ikemiya Y, Inoue T, Iseki C, Kinjo K, Takishita S: Significance of hyperuricemia as a risk factor for developing esrd in a screened cohort. Am J Kidney Dis 2004;44:642-650.

2 Iseki K, Oshiro S, Tozawa M, Iseki C, Ikemiya Y, Takishita S: Significance of hyperuricemia on the early detection of renal failure in a cohort of screened subjects. Hypertens Res 2001;24:691-697.

3 Weiner DE, Tighiouart H, Elsayed EF, Griffith JL, Salem DN, Levey AS: Uric acid and incident kidney disease in the community. J Am Soc Nephrol 2008;19:1204-1211.

4 Chonchol M, Shlipak MG, Katz R, Sarnak MJ, Newman AB, Siscovick DS, Kestenbaum B, Carney JK, Fried LF: Relationship of uric acid with progression of kidney disease. Am J Kidney Dis 2007;50:239-247.

5 Hong Q, Qi K, Feng Z, Huang Z, Cui S, Wang L, Fu B, Ding R, Yang J, Chen X, Wu D: Hyperuricemia induces endothelial dysfunction via mitochondrial $\mathrm{Na}^{+} / \mathrm{Ca}^{2+}$ exchanger-mediated mitochondrial calcium overload. Cell Calcium 2012;51:402-410.

6 Khosla UM, Zharikov S, Finch JL, Nakagawa T, Roncal C, Mu W, Krotova K, Block ER, Prabhakar S, Johnson RJ: Hyperuricemia induces endothelial dysfunction. Kidney Int 2005;67:1739-1742.

7 Johnson RJ, Kang DH, Feig D, Kivlighn S, Kanellis J, Watanabe S, Tuttle KR, Rodriguez-Iturbe B, HerreraAcosta J, Mazzali M: Is there a pathogenetic role for uric acid in hypertension and cardiovascular and renal disease? Hypertension 2003;41:1183-1190.

8 Zhou X, Matavelli L, Frohlich ED: Uric acid: Its relationship to renal hemodynamics and the renal reninangiotensin system. Curr Hypertens Rep 2006;8:120-124.

9 Gomez DM: Evaluation of renal resistances, with special reference to changes in essential hypertension. J Clin Invest 1951;30:1143-1155. 


\section{Kidney \\ Blood Pressure Research}

Kidney Blood Press Res 2015;40:315-322

\begin{tabular}{l|l}
\hline DOI: $10.1159 / 000368507$ & (C) 2015 S. Karger AG, Basel
\end{tabular}

Published online: June 08, 2015

www.karger.com/kbr

10 Isshiki T, Amodeo C, Messerli FH, Pegram BL, Frohlich ED: Diltiazem maintains renal vasodilation without hyperfiltration in hypertension: Studies in essential hypertension man and the spontaneously hypertensive rat. Cardiovasc Drugs Ther 1987;1:359-366.

11 Kimura G, London GM, Safar ME, Kuramochi M, Omae T: Glomerular hypertension in renovascular hypertensive patients. Kidney Int 1991;39:966-972.

12 Nagai T, Kimura G, Matsuoka H, Sanai T, Imanishi M, Kawano Y, Kojima S, Yoshida K, Abe H, Ashida T, et al.: [estimation of the intrarenal hemodynamics in patients with primary aldosteronism]. Nihon Jinzo Gakkai Shi 1989;31:235-241.

13 Kojima S, Fujii T, Ohe T, Yoshitomi Y, Kuramochi M, Shimomura K, Omae T: Glomerular hemodynamics during supraventricular tachycardia. Jpn Heart J 1995;36:429-437.

14 Tsuda A, Inaba M, Ichii M, Ochi A, Ohno Y, Nakatani S, Yamada S, Mori K, Tahara H, Ishimura E: Relationship between serum tsh levels and intrarenal hemodynamic parameters in euthyroid subjects. Eur J Endocrinol 2013;169:45-50.

15 Tsuda A, Ishimura E, Ohno Y, Ichii M, Nakatani S, Mori K, Fukumoto S, Emoto M, Inaba M: Significant association of poor glycemic control with increased resistance in efferent arterioles--study of inulin and para-aminohippuric acid clearance in humans. Diabetes Res Clin Pract 2014;104:234-240.

16 Horio M, Imai E, Yasuda Y, Hishida A, Matsuo S: Simple sampling strategy for measuring inulin renal clearance. Clin Exp Nephrol 2009;13:50-54.

17 Fliser D, Dikow R, Demukaj S, Ritz E: Opposing effects of angiotensin ii on muscle and renal blood flow under euglycemic conditions. J Am Soc Nephrol 2000;11:2001-2006.

18 Kimata S, Mizuguchi K, Hattori S, Teshima S, Orita Y: Evaluation of a new automated, enzymatic inulin assay using d-fructose dehydrogenase. Clin Exp Nephrol 2009;13:341-349.

19 Fliser D, Zeier M, Nowack R, Ritz E: Renal functional reserve in healthy elderly subjects. J Am Soc Nephrol 1993;3:1371-1377.

20 Guidi E, Cozzi MG, Minetti EE, Civati G, Busnach G, Brando B: Effect of familial hypertension on glomerular hemodynamics and tubulo-glomerular feedback after uninephrectomy. Am J Hypertens 2001;14:121-128.

21 American Diabetes Association: Diagnosis and classification of diabetes mellitus. Diabetes Care 2013;36:S67-74.

22 Sanchez-Lozada LG, Tapia E, Avila-Casado C, Soto V, Franco M, Santamaria J, Nakagawa T, Rodriguez-Iturbe B, Johnson RJ, Herrera-Acosta J: Mild hyperuricemia induces glomerular hypertension in normal rats. Am J Physiol Renal Physiol 2002;283:F1105-1110.

23 Sanchez-Lozada LG, Tapia E, Santamaria J, Avila-Casado C, Soto V, Nepomuceno T, Rodriguez-Iturbe B, Johnson RJ, Herrera-Acosta J: Mild hyperuricemia induces vasoconstriction and maintains glomerular hypertension in normal and remnant kidney rats. Kidney Int 2005;67:237-247.

24 Fathallah-Shaykh SA, Cramer MT: Uric acid and the kidney. Pediatr Nephrol 2014;29:999-1008.

25 Nashar K, Fried LF: Hyperuricemia and the progression of chronic kidney disease: Is uric acid a marker or an independent risk factor? Adv Chronic Kidney Dis 2012;19:386-391.

26 Kang DH, Chen W: Uric acid and chronic kidney disease: New understanding of an old problem. Semin Nephrol 2011;31:447-452.

27 Kohagura K, Kochi M, Miyagi T, Kinjyo T, Maehara Y, Nagahama K, Sakima A, Iseki K, Ohya Y: An association between uric acid levels and renal arteriolopathy in chronic kidney disease: A biopsy-based study. Hypertens Res 2013;36:43-49.

28 Bellomo G, Venanzi S, Verdura C, Saronio P, Esposito A, Timio M: Association of uric acid with change in kidney function in healthy normotensive individuals. Am J Kidney Dis 2010;56:264-272.

29 Madero M, Sarnak MJ, Wang X, Greene T, Beck GJ, Kusek JW, Collins AJ, Levey AS, Menon V: Uric acid and long-term outcomes in ckd. Am J Kidney Dis 2009;53:796-803.

30 Nicholls A, Snaith ML, Scott JT: Effect of oestrogen therapy on plasma and urinary levels of uric acid. Br Med J 1973;1:449-451.

31 Bakris GL, Weir MR: Angiotensin-converting enzyme inhibitor-associated elevations in serum creatinine: Is this a cause for concern? Arch Intern Med 2000;160:685-693.

32 Hollenberg NK, Price DA, Fisher ND, Lansang MC, Perkins B, Gordon MS, Williams GH, Laffel LM: Glomerular hemodynamics and the renin-angiotensin system in patients with type 1 diabetes mellitus. Kidney Int 2003;63:172-178. 